Sharif University of Technology
Scientia Iranica
SCIENTIA
IRAN ICAA

\title{
Clinical interventions of social humanoid robots in the treatment of a pair of high- and low-functioning autistic Iranian twins
}

\author{
A. Taheri ${ }^{a, d}$, A. Meghdari $i^{a, *}$, M. Alemi ${ }^{a, b}$, and H.R. Pouretemad ${ }^{\text {c,d }}$ \\ a. Social \& Cognitive Robotics Laboratory, Center of Excellence in Design, Robotics and Automation (CEDRA), Sharif University \\ of Technology, Tehran, Iran. \\ b. Faculty of Humanities, West Tehran Branch, Islamic Azad University, Tehran, Iran. \\ c. Institute for Cognitive and Brain Sciences (ICBS), Shahid Beheshti University, Tehran, Iran. \\ d. Center for the Treatment of Autistic Disorders (CTAD), Tehran, Iran.
}

Received 25 June 2016; received in revised form 2 December 2016; accepted 20 May 2017

\section{KEYWORDS \\ Social robots; \\ High- and low- \\ functioning autism; \\ Twins with autism; \\ Imitation; \\ Social skills; \\ Joint attention.}

\begin{abstract}
In this paper, the robot-assisted interventions for a pair of fraternal twins with autism, of whom one was high-functioning and the other low-functioning, are presented. Since many genetic and environmental factors were the same for both participants, the effects of individual and group robotic games on these two children with high- and lowfunctioning autism were compared. The results indicated improvement in joint attention skills for both subjects. It was further observed that robot group games had the potential to improve social skills in the subject with high-functioning autism and to lower the amount of stereotyped and detrimental behaviors in the participant with low-functioning autism. The communication of both participants with each other improved, and their mother claimed she observed her children playing a meaningful game together at home for the first time since their birth.
\end{abstract}

(C) 2018 Sharif University of Technology. All rights reserved.

\section{Introduction}

Humanoid social robots have been proven to significantly improve social, motor, and joint attention skills in children with autism [1,2]. Individuals with autism often have problems with their reactions to real-world events and often avoid social interactions and communications [3]. Robots involved in autism treatment have been widely studied [4-19] and found to improve imitation [12,20], joint attention [1,4-6,18,20,21], and communication and social interaction [1,5,22-24] skills

*. Corresponding author. Tel: +982166165541 E-mail addresses: taheri@mech.sharif.edu (A. Taheri); meghdari@sharif.edu (A. Meghdari); alemi@sharif.edu (M. Alemi); h-pouretemad@sbu.ac.ir (H.R. Pouretemad)

doi: $10.24200 /$ sci. 2017.4337 in people with ASD (Autism Spectrum Disorders) even during a short number of robot-assisted intervention sessions. Scassellati et al. [1] have provided a valuable review of the different robots used in autism research so far and investigated factors like physical appearance of the robots and human-robot interactions. In this type of research, participants with autism interact with a group of therapeutic items/games directed by a hand-made [1,6,10,23] / commercial [5,13-15] robot and the impacts of the scenarios on the children's performance as well as their different cognitive and social skills are reported over time [5-7,10,13,14,17]. Feil-Seifer and Matarić [10] used the Bandit robot in intervention sessions as a catalyst for social behavior and investigated the interactions of the subjects with ASD. Kholsa et al. [17] used the Lucy robot to improve the engagement and reciprocity of two young adults during a home-based care study. Salvador et al. [15] 
worked on investigating the eye-gaze patterns of typically developing children and children with ASD while interacting with a NAO robot, and tried to present a mathematical modeling of their gaze patterns in speaking and listening contexts.

Investigating twins with autism has always been an interesting topic for psychologists in order to learn more details about autism neurodevelopmental disorder [25-37]. By investigating 42 pairs of twins, where at least one was diagnosed with autism spectrum disorders, Folstein and Rutter in the United Kingdom [26] and Steffenburg et al. in Nordic countries [27] studied concordance rates for autism and cognitive disorders as well as perinatal hazards to the subjects. Their main goal was moving forward in research on the aetiology of autism. Previous research on autism spectrum disorder conducted on twins, without robots, has mainly focused on the relative effects of genetics and environment [28-30], autistic traits in twins [31-33], and comparing the monozygotic (MZ) and dizygotic (DZ) twins with autism $[26,27,34]$. Bailey et al. [35] investigated the prevalence of the fragile $\mathrm{X}$ anomaly in twins with ASD. Sultana et al. [36] claimed that they identified/characterized a novel gene in a monozygotic pair of twins with autism. Contrary to the extensive basic research on twins with autism, there have been less studies on the clinical behavioral treatment of twins with ASD [25,37,38]. In 1975, Kean [25] studied the development of social skills of a pair of boys with autism. Hiton and Seal [37] investigated the communication and behavioral performances of a pair of monozygotic twins with autism during a 16intervention session pilot study. After their trial interventions in DIR (Developmental, Individual-Difference, Relationship-Based Model) and ABA (Applied Behavioral Analysis), and comparing the questionnaire results with their clinical observations, they indicated a slight gain in CSBS (Communication and Symbolic Behavioral Scales) questionnaire scores of the ABA child. However, to the best of our knowledge, including a humanoid robot in twins' autism treatment has not been reported so far. What makes this study different is that it focuses on the robot-assisted interventions for seven-year old fraternal twins with autism, of whom one is high-functioning and the other low-functioning. The benefit of investigating twins, in comparison with other cases, is having identical factors such as parents, food, clothing, and education, which are not commonly possible to control in a general research. Moreover, most of the studies done in the field of autism (especially by roboticists) investigate children with high-functioning autism $[1,4,15]$ and there are less articles on simultaneous study of subjects with highfunctioning and/versus low-functioning autism [20,39]. The main goal of this research was to investigate how the effects of robot-assisted autism therapy could differ for children with high- and low-functioning autism. In addition, improving the cognitive and communication skills of the two subjects with each other and with their parents during various therapeutic scenarios was investigated through our case-study interventions. Moreover, behavioral analysis of the twin subjects was quantitatively performed through intervention movies.

\section{Research methodology}

\subsection{Participants}

The participants consisted of a pair of male seven-yearold fraternal twins diagnosed with autism spectrum disorders. The first, S1-A, was high functioning while the second, S2-I, was low-functioning. The subject S1-A had mild verbal skills, spoke his first words one year later than normally developing children, and had experienced hyperactivity and eye-contact-avoidance from an early age. The low-functioning twin, S2-I, had a more severe case of autism. He had poor verbal skills with $\mathrm{MLU}<3$ (Mean Length of Utterance) and often engaged in repetitive fluttering fingers, and nonpurposeful and stereotyped behaviors.

\subsection{Intervention sessions}

The intervention scenarios were designed prior to the study and included the humanoid $\operatorname{robot}(\mathrm{s})$, the twins, their parents, therapist, and robot operator in a friendly environment. The goal of our clinical interventions in this study was to engage the boys in different individual and group imitation and joint attention situations. The participants attended two sessions per week for a total of 12 thirty-minute sessions in all. The treatments were held at the Social \& Cognitive Robotics Laboratory at Sharif University of Technology.

\subsection{Experimental setup}

The treatments were held in a $5 \times 5 \times 3 \mathrm{~m}^{3}$ room. The experimental setup was made up of one or occasionally two humanoid robots. In addition, there were two laptops, two cameras (for filming sessions), Microsoft Kinect Sensor, a video-projector, and a whiteboard and chairs for all involved. A single subject design [40] using the Wizard of Oz style robot control (without having a control group) was selected for this study. ChildRobot interactions were preset and structured following defined purposes. All instructions were given by the robot and/or the therapist. The schematic and real setup of our study are shown in Figures 1 and 2.

The twins' parents were neither paid nor had to pay for the sessions and were acting as volunteers. In addition to upholding moral obligations, both the parents and the researchers signed a pledge/consent form before the interventions began. 


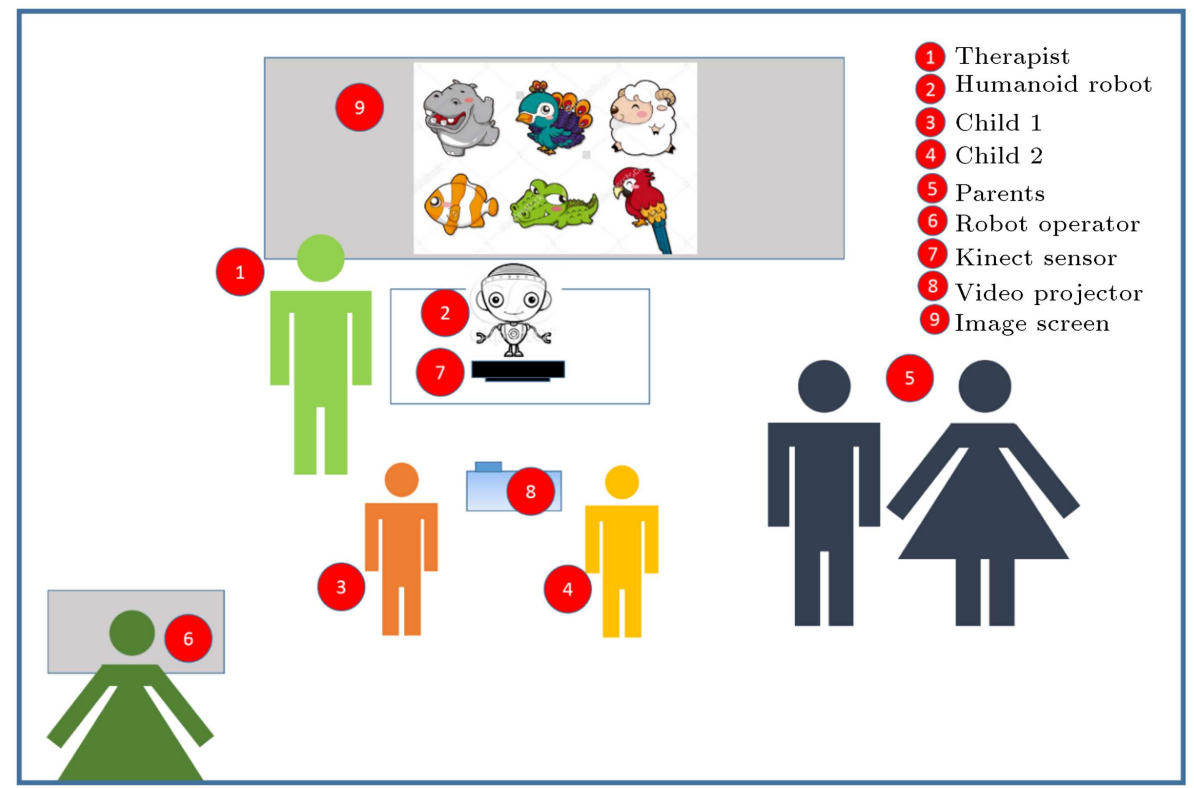

Figure 1. Schematics of the experimental setup: human-robot clinical interventions.

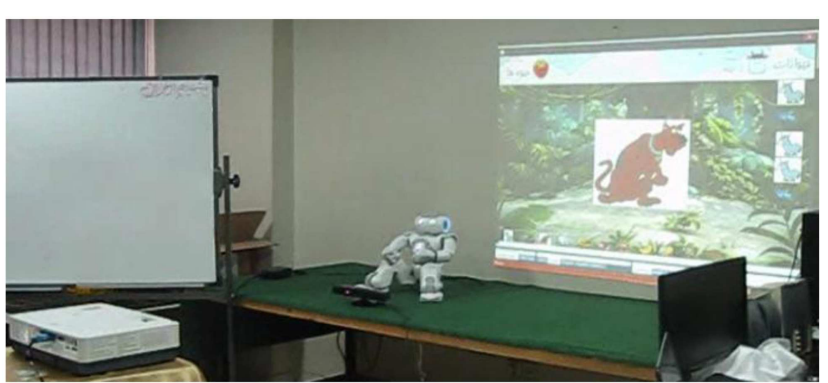

Figure 2. The human-robot intervention room.

\subsection{Humanoid robots}

A NAO-H21 humanoid robot with 21 degrees of freedom manufactured by the Aldebaran Company [41] was used in our educational-therapeutic programs. It was renamed "Nima", a Persian boy's name, for use in the Iranian context. We also used the Alice-R50 robot, which we renamed "Mina", a Persian girl's name. Mina had 32 degrees of freedom and was created by the Robokind Company [42]. These two robots have been used in many different autism studies worldwide, and were found to have the capabilities needed for our designed intervention scenarios [4,5,13-15]. Although the majority of our work centered on the Nima robot, we included the Mina robot because it was able to show different facial expressions (having 11 DOFs in the face) as well as allowed us to determine if a different robot would affect the children's results (Figures 3 and 4).

\subsection{Therapeutic games}

Children with autism are often impaired in imitation and motor skills [1,5], initiating/responding to joint attention behaviors $[2,3,6,18]$, and initiating interactions/communications $[1-3,10]$. To investigate the

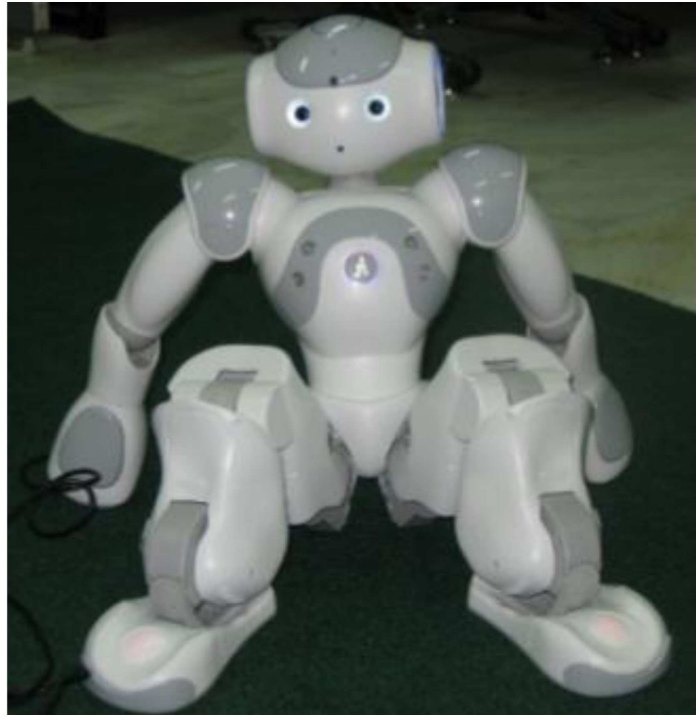

Figure 3. NAO (Nima) robot.

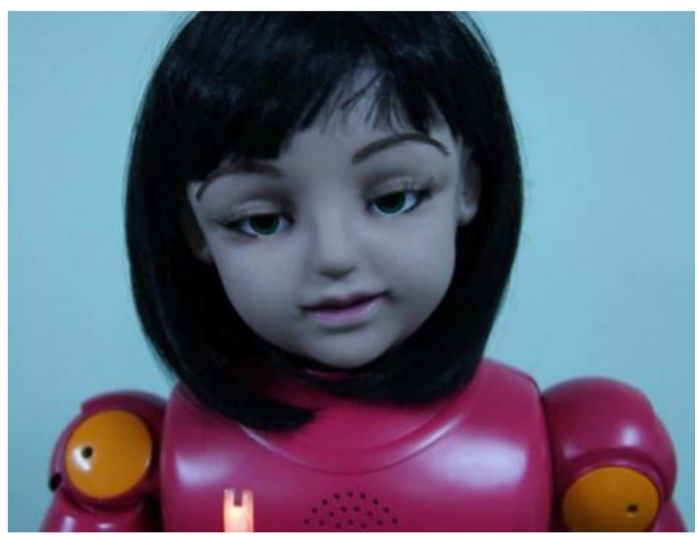

Figure 4. Alice-R50 (Mina) robot. 
Table 1. List of the therapeutic games.

\begin{tabular}{|c|c|c|c|}
\hline$\#$ & Games & Modes & Main purposes of the game \\
\hline 1 & $\begin{array}{l}\text { Teaching imitation and motor } \\
\text { skills by the robot to the children } \\
\text { through individual or group } \\
\text { exercise and dances }\end{array}$ & $\begin{array}{l}\text { Robot-Child } \\
\text { Robot-Child-Brother/Parent }\end{array}$ & $\begin{array}{l}\text { - Movement imitation } \\
\text { - Dyadic/triadic interactions }\end{array}$ \\
\hline 2 & $\begin{array}{l}\text { Real-time imitation of the robot } \\
\text { by the child in upper body } \\
\text { movements }\end{array}$ & Robot-Child & $\begin{array}{l}\text { - Drawing the attention of the child to } \\
\text { the robot and therapist }\end{array}$ \\
\hline 3 & $\begin{array}{l}\text { Tele-operating the humanoid } \\
\text { robots' head and arms using a } 6 \text { - } \\
\text { DOFs haptic Phantom-Omni } \\
\text { robot as a remote controller }\end{array}$ & Robot-Child & $\begin{array}{l}\text {-Empowering the children and } \\
\text { therapist to move the robots' joints } \\
\text { arbitrarily } \\
\text { - Dyadic/triadic interactions } \\
\text { - Turn-taking games }\end{array}$ \\
\hline 4 & $\begin{array}{l}\text { Kinect-based recognition game: } \\
\text { classification of fruits/animals } \\
\text { by pointing to different baskets } \\
\text { on the screen }\end{array}$ & $\begin{array}{l}\text { Child } \\
\text { Robot-Child } \\
\text { Robot-Child-Parent }\end{array}$ & $\begin{array}{l}\text { - Classification } \\
\text { - Joint attention and pointing } \\
\text { - Gaze-shifting }\end{array}$ \\
\hline 5 & $\begin{array}{l}\text { Playing a developed Kinect- } \\
\text { based virtual xylophone on the } \\
\text { screen }\end{array}$ & Child-Parent/Therapist & $\begin{array}{l}\text { - Movement imitation } \\
\text { - Joint attention } \\
\text { - Visual pursuit }\end{array}$ \\
\hline 6 & Playing a real xylophone & Robot-Child & $\begin{array}{l}\text { - Imitation } \\
\text { - Joint attention } \\
\text { - Turn-taking } \\
\text { - Eye-hand coordination }\end{array}$ \\
\hline
\end{tabular}

potential benefits and different effects of roboticinterventions on the subjects with high- and lowfunctioning autism, a variety of therapeutic games based on autistic impairments have been developed. The scenarios/games are designed based on Applied Behavioral Analysis (ABA) [37]. These games concentrate on affecting different cognitive skills, imitation, joint attention, social skills, eye-contact, and turntaking of children with ASD and their potential effectiveness has been confirmed by clinical child psychologists. The twins participated in some of these games at each session in different modes: RobotChild or Robot-Child-Brother/Parent/Therapist interactions. The game list is presented in Table 1. All of the therapeutic games were developed by our research group. We did the programming in C\#, JAVA, NAO platform Choregraphe (by Aldebaran Co.) [41], and Workshop Software (by Robokind Co.) [42]. In games \#1, \#4 in the Robot-Child/Parent mode, and \#6, the robot's engagement was much more than in the other games and its actions/decisions during the mentioned games directly affected the twins' performance. In the other games (\#2-\#5), the robot was more likely to be a follower, companion, or reinforcement tool, not necessarily a teacher.

Either the robot and/or the therapist gave the instructions for each game to the children and their parents. Table 1 shows the games the robot played with the children. In these games, the robot asked the twins to attempt imitation or joint attention tasks. 


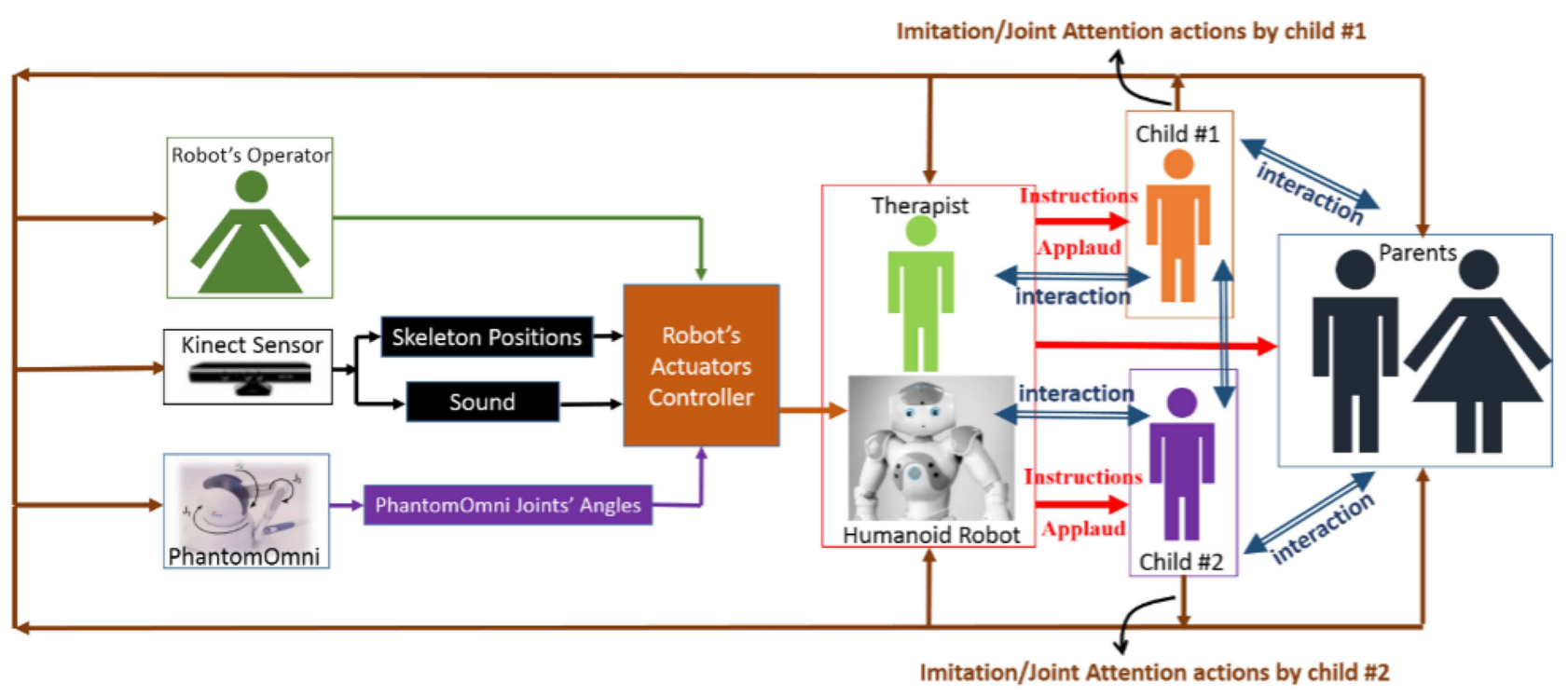

Figure 5. The modular structure of the robot-assisted clinical interventions.

The robot was controlled by actuator commands sent in two ways. The first method was manual control by an operator, and in the second method, feedback from the Kinect sensor or haptic Phantom-Omni encoders was processed and sent back to the robot automatically. Whether the child completed a task correctly or not, the robot provided verbal reinforcement encouraging the twins or gave them a big round of applause for their efforts. The structure of our robot-assisted interventions is shown in Figure 5.

\subsection{Assessment tools}

The 4 instruments used to measure the effects of the humanoid social robot on the children were the following.

\subsubsection{Gilliam Autism Rating Scale (GARS)}

Developed by Gilliam in the 1990s, this is one of the most widely used scales for autism diagnosis and assessment [43]. The GARS scale is broken down into 4 subscales: Stereotyped Behaviors, Communication, Social Interactions, and Developmental Disturbances. It has been established that the Cronbach's alpha coefficients for the subscales are 0.90 for stereotyped behaviors, 0.89 for communication, 0.93 for social interactions, and 0.88 for developmental disturbances and for autism typology, it is 0.96 [44]. After studying the GARS in Iran on 100 children, the Cronbach's alpha for the 4 subscales and overall test was $0.74,0.92$, $0.73,0.80$, and 0.89 , respectively [45].

\subsubsection{Quantitative content analysis of intervention video records}

Quantitative content analysis is a powerful tool to analyze written texts, videos, or other media. This method is systematic, flexible, and replicable and has been used by specialists $[46,47]$. Intervention video records were observed and rated by 2 psychologists to analyze the twins' behaviors during the sessions. To this end, among the different social and cognitive impairments of individuals with autism, 5 items and criteria were extracted based on 3 valid questionnaires: GARS [39], Autism Treatment Evaluation Checklist [48], and Autism Social Skills Profile [49,50]. The 5 items rated by the psychologists consisted of: 1) joint attention, pointing, and gaze shifting; 2) imitation; 3) maladaptive behaviors; 4) verbal and nonverbal communications; and 5) instruction perception and cooperation.

Although the content analysis was timeconsuming and costly, it gave us worthwhile behavioral patterns of the participants. The two psychologists separately observed and rated the behavior of each child during all the intervention sessions. The means of their scores, which had meaningful correlation, are presented in the Results Section. Each child received a score of +1 for every correct task based on the extracted criteria. These tasks could be done following the designed intervention scenarios presented in Tables 1 and 2 (i.e., following the games' instructions) or the child's creativity. Judges scored -1 when a given assignment was not done or was done incorrectly by each participant. The significant unit of each category occurred during the whole task and the time interval of the tasks was not a criterion for our evaluations. Our judges tried their best to have the least amount of human error in the quantitative content analysis scoring.

\subsubsection{Human's assessment of behaviors}

A clinical child psychologist assessed the children's autistic behaviors both one week prior and one week after the intervention sessions (as pre- and post-tests) 
Table 2. Intervention sessions schedule; the letters R, P, and T stand for Robot, Parent, and Therapist, respectively.

\begin{tabular}{|c|c|c|c|c|c|c|c|}
\hline \multirow[t]{2}{*}{ Session } & \multirow[t]{2}{*}{ Game \#/Mode } & \multicolumn{5}{|c|}{ Participants in the Game } & \multirow[t]{2}{*}{ Description } \\
\hline & & S1 & $\mathrm{S} 2$ & $\mathrm{R}$ & $\mathrm{P}$ & $\mathrm{T}$ & \\
\hline 1 & Orientation Session & & & & & & Nima and Mina performed their capabilities \\
\hline 2 & \#4/ Robot-Child & & & & & & S2-I did not take part in the game \\
\hline \multirow[t]{3}{*}{3} & \#2/ Robot-Child & & & & & & \multirow[t]{2}{*}{ Mina was also used in this session } \\
\hline & \#1/ Robot-Child & & & & & & \\
\hline & \#3/ Robot-Child & & & & & & \\
\hline \multirow[t]{2}{*}{4} & \#5/ Child-Therapist & & & & & & \multirow{2}{*}{$\begin{array}{l}\text { Robot applauded them for the correct task. } \\
\text { S1-A intervened in his twin's game }\end{array}$} \\
\hline & & & & & & & \\
\hline 5 & \#6/ Robot-Child & & & & & & \\
\hline 6 & \#3/ Robot-Child & & & & & & Game \#3 was selected at the request of the twins \\
\hline 7 & \#1/ Robot-Child-Child & & & & & & Difficulty level of the tasks: Easy \\
\hline 8 & \#1/ Robot-Child-Child & & & & & & Difficulty level of the tasks: Medium \\
\hline 9 & \#1/ Robot-Child-Parent & & & & & & S2-I was absent from this session \\
\hline 10 & \#1/ Robot-Child-Child & & & & & & Difficulty level of the tasks: Hard \\
\hline \multirow[t]{3}{*}{11} & \#1/ Robot-Child-Parent & & & & & & Difficulty level of the tasks: Medium \\
\hline & \#4/ Child-Parent & & & & & & \\
\hline & & & & & & & \\
\hline
\end{tabular}

for a specialist assessment of the effect of the robot interventions.

\subsubsection{Interview with the parents}

Due to existence of the opportunity for the children to show novel social behaviors [1] outside the study environment, we had the parents, who spent extensive time with their children, informing us of any behavioral changes they might observe. An interview with the parents took place at the end of the program in order to obtain information on the effects of 1) using robots in autism treatment, 2) their own attitude and degree of parental stress concerning their children after treatments, and 3) the session's impact on each child's social skills and communication between themselves and with others.

\section{Results and discussions}

Table 2 presents the schedule of our 12 intervention sessions. The first session consisted of introducing the humanoid robots and showing their capabilities to the twins and their parents. The robots greeted the children and tried to cheer them up by dancing, singing songs, calling their names, shaking hands, etc. They were given a short description of the plans for the following intervention sessions. During sessions 2 to 6 , each child participated in robotic games individually. In sessions $7-11$, in addition to complicating the design 
of our individual games, we also engaged both of the twins simultaneously in group games to survey their communication with each other; sometimes, one of the parents was also included in group games with one of their children. We observed noteworthy results in the group games, which will be presented in the following subsections of the paper.

In the second session, S2-I did not take part in the games at all. He was wandering around the room distracted by other devices. His low scores in session 2 are because of his lack of participation. S1-A did the fruit/animal recognition game very well. He also responded to his mother's hints during game \#4.

In session 3, S2-I engaged in the games at the request of the therapist. At first, both of the children participated in game \#2, in which the Nima robot imitated their upper body movements; this game cheered up the twins and their parents. It can be noted that the robot's imitation of the child was done through online analysis of the Kinect skeleton data using inverse kinematics formulations [5]. After that, S1-A controlled both humanoid robot's movements remotely using the Haptic Phantom-Omni robotic arm. Enjoying the game while having some gaze-shifting from the humanoid robots to the mother was the most important observation regarding S1-A's behavior during this game. It should be noted that game \#3 was selected as the best game by the twins at the end of the 12 intervention sessions. Next, while playing game \#1, S2-I had a great number of mistakes in imitating and joint attention tasks. He did not follow the robot's oral instructions well and made several movements that he expected the robot to imitate. This could be explained by two reasons; it was his first time participating in robot-assisted games, and/or instructions for game \#1 and game \#2 were possibly confusing.

In Sessions 4 and 5, the children were involved in playing a virtual and a real xylophone. The children were required to imitate the therapist or the robot in hitting different colored bars of the instrument intermittently. The most important achievement of these sessions was the great potential of music-teaching scenarios in improving imitation and joint attention skills of children with autism. Both of the twins did their tasks acceptably in these imitation turn-taking games; however, in session 4, S2-I's twin brother intervened and his game was terminated in the middle as it was not possible to finish the game individually.

In session 6 , at $\mathrm{S} 1-\mathrm{A}$ 's request, we ran game \#3 for the second time. For each child, the game finished when the robot fell because of the child's motions.

During sessions 7-11, we concentrated on teaching motor skills and exercise to the twins through group imitation games using the Nima robot. During these sessions, the humanoid robot performed some regular exercises and asked the twins to imitate him. There were a variety of combined head, arms, and legs motions the children needed to imitate simultaneously. The parents were also engaged in the robotic games as a playmate of their son for the first time in session 9 . The interesting observations in the group imitation games was the increase in the twins' attention, gaze-shifting, and even verbal communication with each other, their parents, and the robot. It should be noted that S2-I was absent in session 9 and his game was postponed to the 11th session. In addition, in session 11, both of the children participated in the fruit/animal recognition game (game \#4) in Mother-Child and Robot-Child modes. During game \#4, each participant needed to put/classify the picture on the screen in the fruit/animal baskets by pointing to convenient baskets on his/her left or right. In group modes, both of the players needed to do the correct task simultaneously in order to progress to the next step. During MotherChild mode, S1-A did all of his tasks correctly and was given much applause by the robot. However, S2-I was only able to do the tasks with a precision of $70 \%$. His mother always looked at him and gave S2-I hints and asked her child to point to the correct basket. S2-I rarely looked at his mother spontaneously and only moved his head in the mother's direction when she said "Do it like me! Not that way!". S1-A tried to help his brother as well. In the Robot-Child mode, the Nima robot also participated in the game and pointed to different baskets. The robot intentionally did some of his tasks incorrectly. We wanted to explore the children's reactions to the robots' faults. The results differed for S1-A and S2-I. S2-I never talked to the robot when the robot performed incorrect movements and only sometimes paid attention and saw the robot's actions. He usually waited until the robot corrected its movement. One time, although the robot did its task right, S2-I chose the basket incorrectly. But, S1A's reactions were completely different from his lowfunctioning twin brother. He always acted swifter than the robot and looked at the robot quickly to watch its reaction. When the robot performed an incorrect movement, he shouted excitedly, "No, Nima! You are wrong. That way. That way!' He also hit its head as a punishment for the robot's first fault.

Finally, in the last session, we had a summary review of the previous memorable interventions' movies and watched the animation Wall-E all together. At the end of the 12th session, the twins were given a gift by the Nima robot for their cooperation in the clinical intervention sessions. Figures 6-13 show some snapshots of the intervention sessions at the Social \& Cognitive Robotics Lab (SUT).

Four different measurement instruments including 1) quantitative content analysis of the intervention videos, 2) GARS questionnaire, 3) human assessments, and 4) interview with the parents were used to measure 


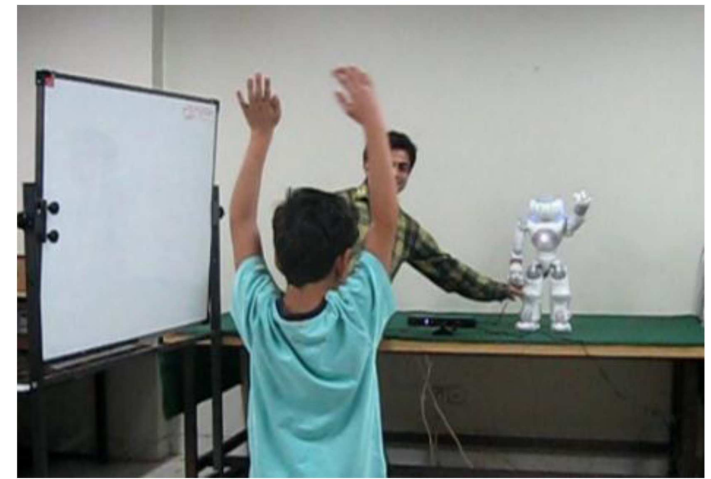

Figure 6. Playing an imitation game in Child-Robot mode in session 3 , game \#1.

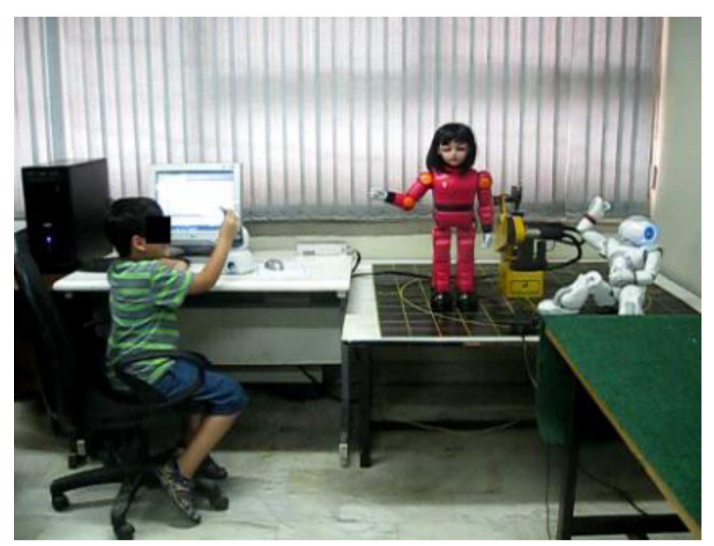

Figure 7. Teleoperating Nima and Mina using the haptic Phantom-Omni robot in session 3, game \#3.

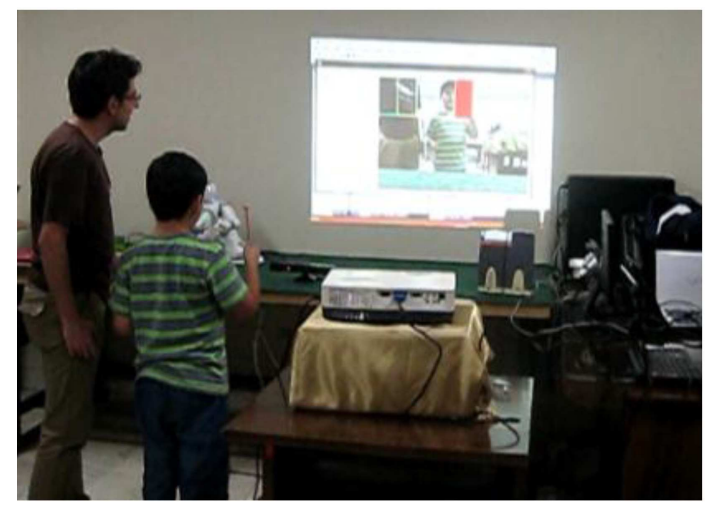

Figure 8. Playing the virtual xylophone in an imitation turn-taking game in Child-Therapist mode in session 4, game \#5.

the effects of the interventions. Each of the mentioned instruments had its own advantages/disadvantages. We used different assessment tools simultaneously to cover any weaknesses.

\subsection{Quantitative content analysis}

Based on the video records and the obtained data, the most important findings are as follows.

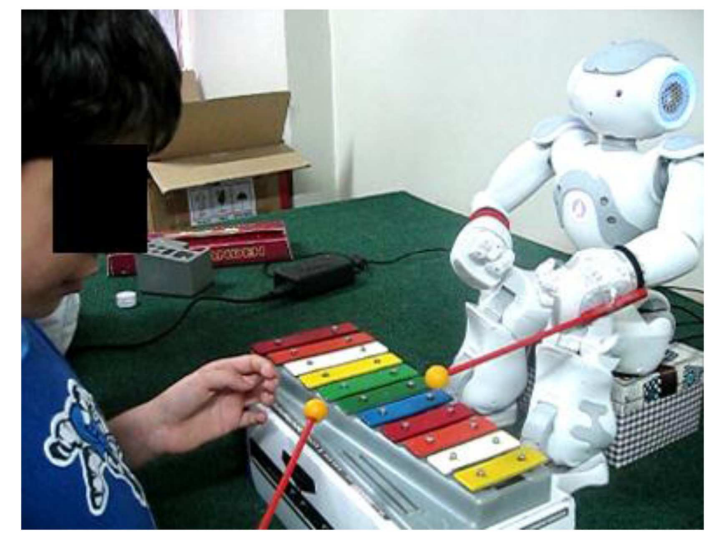

Figure 9. Playing the real xylophone in a joint attention imitation turn-taking game in session 5 , game \#6.

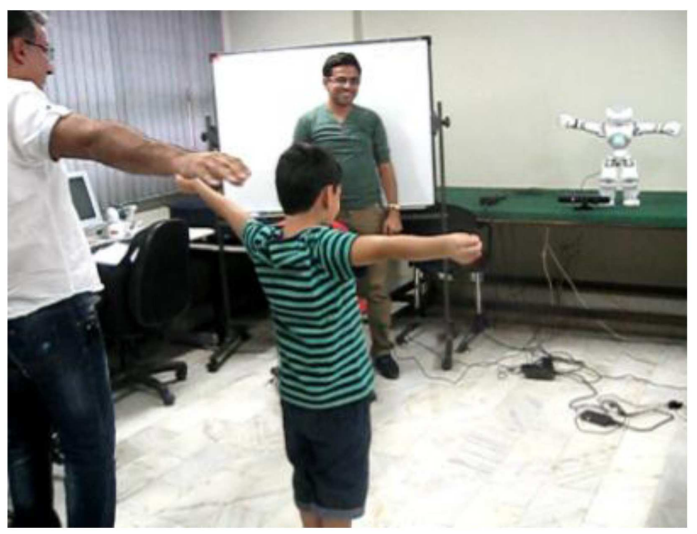

Figure 10. Nima teaching imitation and motor skills to a child and his parent in session 9, game \#1.

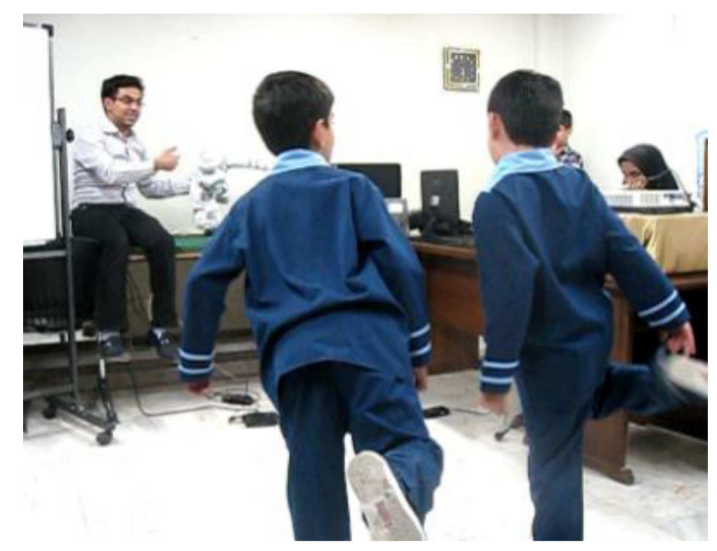

Figure 11. The twins imitating the robot in a group game in session 10 , game \#1.

\subsubsection{Joint attention}

Joint attention tasks included eye contact, pointing to far and near points, and gaze-shifting between two situations. Joint attention behaviors occurred more often in the fruit/animal recognition game, group modes of game \#1, and the virtual and real xylophone games. In order to quantify the joint attention skills 


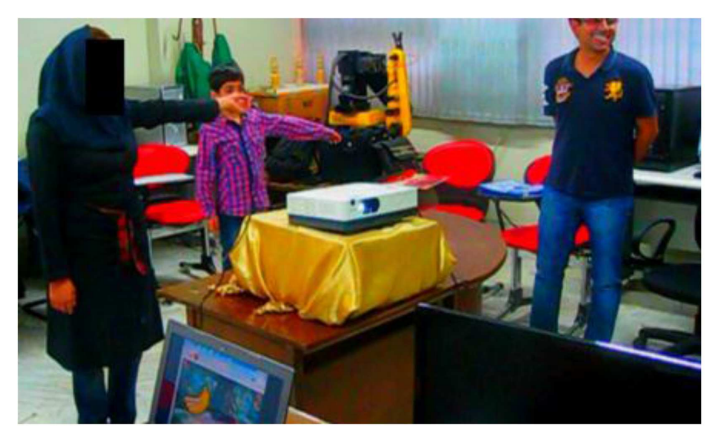

Figure 12. Animal and fruit recognition game in Child-Parent mode in session 11, game \#4.

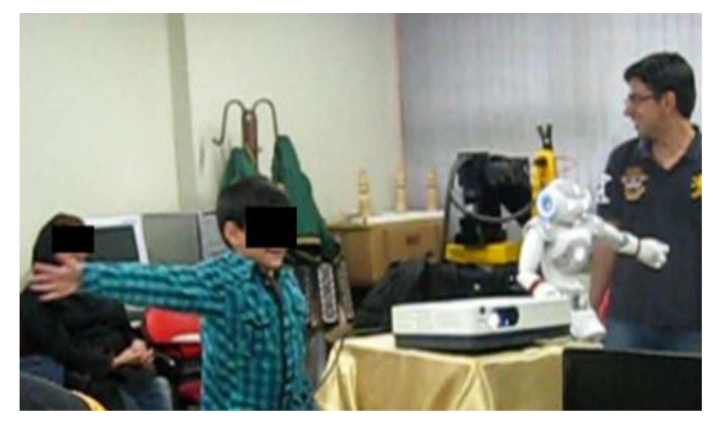

Figure 13. Animal and fruit recognition game in Child-Robot mode in session 11, game \#4.

of the twins, the child clinical psychologists scored the following parameters after watching the intervention sessions' video records: JA1-a) gaze-shifting rate of each child toward the robot, the parent/therapist, and his twin brother; JA1-b) gaze/points following rate of each child from the robot, therapist/parent, and the other child; and JA2) pointing to far/near points. Unfortunately, our judges could not score the eye contact and gaze fixation of the twins with the robots and people in the room manually. By dividing the averaged psychologists' scores from each session's observation to the sum of all the mean JA1 scores for each participant and, then, multiplying by 100 , the percentage scores of JA1 for S1-A and S2-I versus session numbers were calculated, which are presented in Figure 14(a) and (b). It should be noted that the total JA1 behaviors observed in S1-A were 3.2 times those of S2-I.

Analysis of variance was done on simple linear regression models for each graph using Minitab Software [51] to investigate whether the observed increasing trend in JA1-total scores versus time for both of the twins (Blue graph in Figure 14(a) and (b)) was significant. We applied an ANOVA test for the overall $F$-test of the regression analysis in order to find out the overall adequacy of the linear regression models. The associated $p$-values for the overall $F$ test of both models were 0.02 and $0.02(<0.05)$, respectively; thus, we could be confident that some

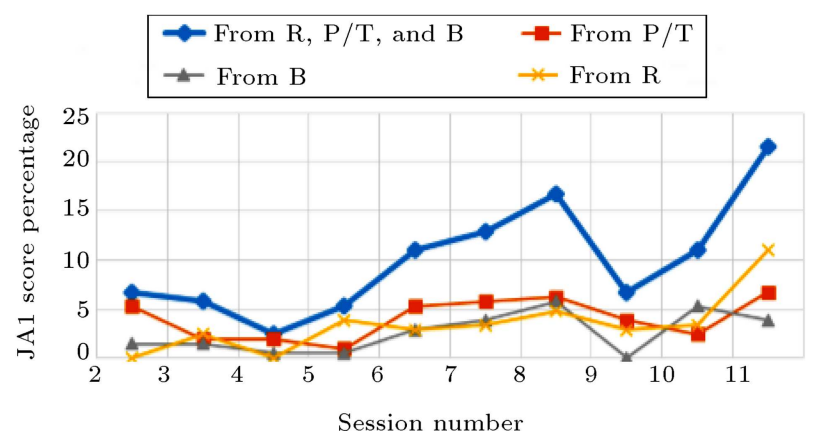

(a)

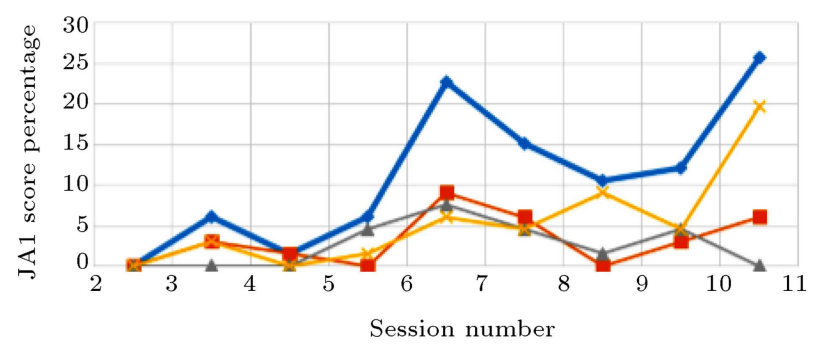

(b)

Figure 14. Percentage of the sums of gaze-shifting and gaze/points following scores toward/from the Robot (R), the Parent/Therapist $(\mathrm{P} / \mathrm{T})$, and the Brother $(\mathrm{B})$ for $(\mathrm{a})$ S1-A and (b) S2-I.

linear relationship existed between the "JA1-scores" of the twin brothers and the "treatment time". The calculated slopes associated with treatment time (session numbers) were positive numbers of 0.3704 and 0.2589 , along with $p$-values of 0.02 and $0.02(<0.05)$, respectively. Therefore, Figure $14(\mathrm{a})$ and (b) indicate that both of the twins seemed to show an improving trend in terms of gaze shifting toward as well as gaze following of the robot and other individuals in the game room. It should be noted that the observed improved performance could also be due to the change in session's games/instructions. However, based on clinical child psychologists' advice, we considered the fact that the "learning effect" most likely occurred for the subjects with autism after being involved in a game; and repeating that game with the same difficulty level might seriously affect their scores and performance. Therefore, to prevent this issue, our strategy was to conduct hierarchical and easy-to-difficult-level games as much as possible during the time. In this step, the observed trend of the JA-skills scores should be taken with caution before making any strong claims on improvement in joint attention behaviors of the subjects; however, they could be a clue for comparison/confirmation with/of the human assessments reports on joint attention behaviors (which will be presented in Subsection 3.3). The improvement in joint attention skills of children with autism has also been reported in both types of the research done with robots $[6,18,52]$ and without robots $[3,53]$. 
As it is shown in Figure 14(a), the JA1 scores of S1-A from the parent/therapist are approximately constant, with a slight increase during game \#1 group modes. However, interestingly, the attention of S1-A toward his twin brother increased with a remarkable slope from Session 5. In most of the sessions, the gaze shift score of S1-A toward his parent was greater than that toward the robot. The noteworthy result of Figure 14(a) is the performance of the child in session 11; his total JA1 score was $21.5 \%$, which means that in this one session, he showed more than one-fifth of all his gaze-shifting and gaze/point following behaviors for all the robotic-assisted intervention sessions. This may be due to the great potential of the designed joint attention recognition game, and the positive effect of involving the parent and the robot with its intentional mistakes in a group turn-taking game.

In the regression analysis done using Minitab, the total JA1 score of S2-I in session 6 was considered an unusual observation. This performance may be due to accepting the twins' request to re-run game \#3 in that session. Increase in S2-I's sense of being empowered to control the robots as well as many joint attention situations provided for him to get involved in a happy environment may have affected the lowfunctioning subject's performance. His gaze shifting percentage toward his parent heavily depended on the rate of being called/given hints by his mother/father and it did not follow a specific pattern versus session number. Similar to S1-A, S2-I's maximum total JA1 score as well as the score from the robot occurred in the last session. We believe that the amazing total JA1 score of $25.8 \%$ in that session is due to the additional situations he was involved in, not necessarily because of an unusual improvement in joint attention skills. Contrary to his twin brother's behaviors, S2-I had more gaze shifting toward the robot in the exercise imitation game than in the Robot-Child mode of game \#4. It can also be hypothesized that during the intervention sessions, the friendship between the robots and the child was getting stronger for both twins; therefore, higher attention rates toward the robot were expected. However, unlike S1-A, S2-I never initiated a communication with Nima. He did, however, react to the robot's initiations primarily through non-verbal means with occasional verbal utterances.

The twins' net JA2 scores for certain intervention sessions are shown in Figure 15 . The $x$-axis contains the session numbers in which each child specifically played the designed joint attention games: the fruit/animal recognition game (game \#4) and playing the virtual xylophone (game \#5). Unfortunately, because of the small amount of data, no statistical analysis could be applied to the JA2 scores to investigate whether the ascending trend was statistically significant.

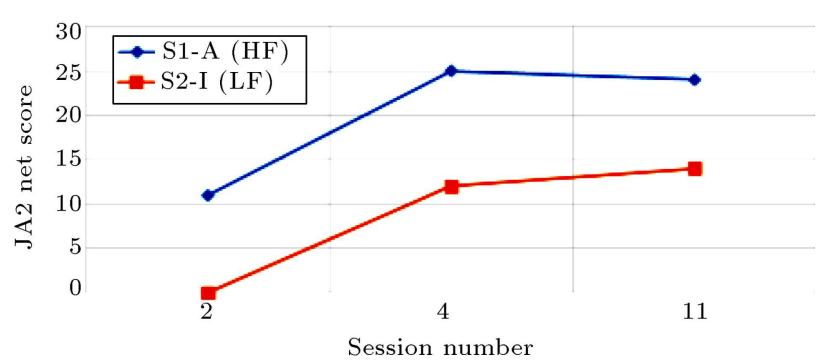

Figure 15. Pointing to far/near points net (the resultant of positive and negative JA2) scores by the twins while playing joint attention games.

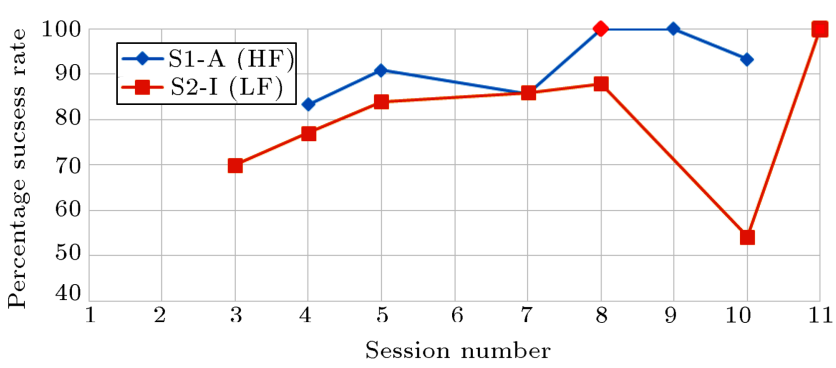

Figure 16. Percentage of success rate of the participants in imitation and exercise games.

The success rates of S1-A's pointing scores based on Figure 15 were $83 \%, 74 \%$, and $100 \%$, respectively. S1-A did not have any problems in recognizing the fruit/animal pictures and the two mistakes made by S1A in session 2 were because of his excitement during the game. However, in session 11, he concentrated on his pointing tasks and tried to help the Nima robot with its (intentional) mistakes while playing the group mode of game \#4. On the other hand, S2-I, who did not attend any games in session 2 , played game \#5 with a success rate of $63 \%$ before his game was interrupted by his twin in session 4; and made 6 mistakes in his 20 pointing tasks in session 11. In contrast to his twin brother, S2I had difficulties in recognizing some of the fruit/animal pictures. Although S2-I's mistakes during the MotherChild mode of game \#4 made the mother frustrated, the twins' parents were totally satisfied with their children's performance in the joint attention games. Our clinical child psychologists respectively observed 7 and 3 arbitrarily pointing behaviors to far/near points by S1-A and S2-I in the second half of the sessions during their video records analysis.

\subsubsection{Imitation}

In the imitation games, the humanoid robot performed a movement and asked the child/children to do the same action. The imitation tasks of the twins from robots included a wide range of easy and difficult actions such as simple gross movement of hands and head, daily exercise, one-leg balance, and hitting the xylophone's bars. Figure 16 shows the success rate percentage of the twins during the imitation games. 
The success rate in each session was calculated by dividing the number of each child's correct tasks by the number of his whole tasks in that session.

It is important to note that both the twin brothers had received previous treatments. Accordingly, their imitations of the robot were quite acceptable. During the imitation games, we faced the ceiling effect for both of the children, especially S1-A. They were both able to imitate almost all of the robots' exercise actions. Figure 16 seems to show an improving trend in the imitation performance of the twins.

The assignment of playing the virtual xylophone game in session 4 was new and appealing for both the twins. To hit the same virtual xylophone bars as the therapist, they had to do a complex cognitive imitation/joint attention task, i.e. looking at the screen and remembering the bar color hit by the therapist and, then, trying to play the same note by virtually touching the right bar. Imitation of the robot's actions in playing a real xylophone was not difficult for either twin in session 5; however, their incorrect actions were in rhythm perception/imitation when the robot hit 3 bars in different time intervals.

Interestingly, both of the children demonstrated very good performance in the group modes of imitation games. The success rate of S1-A and S2-I in the RobotChild-Parent mode with a medium difficulty level was $100 \%$ (indicated by red markers in Figure 16). S2-I did not do very well in the hard exercise in session 10 . His low performance was because of his problems in one-leg balance imitation for 15 seconds, long sequence of the actions, and low mood during the session. Disregarding S2-I's performance in session 10 (as outlier data), linear regression analysis was carried out using Minitab Software to see whether the improving trend observed for his imitation versus intervention time was statistically significant. After applying the statistical test, we observed that the regression model was statistically significant, $F=61.5, p=0.001<0.05$. In S2-I's data in Figure 16, we see that $R^{2}=93.9 \%$, which means the intervention time (session numbers), explains the quite good variability of his imitation success rate. This observation could be helpful in comparison of the psychologist's pre- and post-assessments of S2-I's imitation skills. Improving imitation/motor skills of children with autism through similar types of imitation games, including robot-assisted $[1,12,20]$ and nonrobot-assisted $[54,55]$ studies, has also been reported in the literature, which confirms our tentative finding. Moreover, we did the same analysis for S1-A. The $p$ value for the regression model analysis was $0.130>0.05$ and no significant improvement could be observed in imitation scores of S1-A over time.

Although the focus of the games' design was on imitation skills and joint attention, they may have also had positive effects on other cognitive skills.

\subsubsection{Maladaptive behaviors and social communication}

One of the improvements in S2-I was the decrease in his autistic and maladaptive behaviors, such as fluttering fingers; stereotyped behavior; meaningless repetition of a word/words; echo, ecstasy, and lack of attention to the group; and engaging in solitary interests and hobbies. Although Figure 17 does not show a monotonic trend in S2-I's maladaptive behaviors scores $(F=2.85$, $p>0.05$ for linear regression analysis of variance), it indicates that in the last 4 sessions, the average of the stereotyped scores of S2-I $(<6)$ was less than those in the first and middle 4 intervention sessions. This observation is also investigated (and confirmed) in Subsections 3.2. and 3.3.. The maladaptive scores of S2-I were quite low in the last 3 sessions. Moreover, the clinical psychologists observed 6 occasions of ecstasy and engaging in solitary interests and hobbies in S2$\mathrm{I}$ in the first half of our intervention sessions. We believe that the humanoid robot was able to attract the child's attention and enhance his motivation in participating in the games over time. In other words, the robot's attendance and the vivacious intervention games caused the child with low-functioning autism to forget some of his internal problems and repetitive meaningless stereotyped behaviors. Although we did not design any games to control maladaptive behaviors directly, we observed a reduction in S2-I's echo and stereotyped behaviors throughout our robotic assistive clinical intervention sessions. Tapus et al. [56] also indicated the decrease in stereotyped behaviors of children with autism while interacting with NAO humanoid robot.

S1-A showed almost no maladaptive behaviors; our judges observed only 8 stereotyped behaviors, no meaningless repetition of words, and no ecstasy and lack of attention to the group during the whole sessions.

Additionally, S1-A showed some improvement in verbal communication, social participation, and enjoying group games. Verbal communication scores of S1-A are shown in Figure 18. Again, to investigate whether there was significant relationship between the

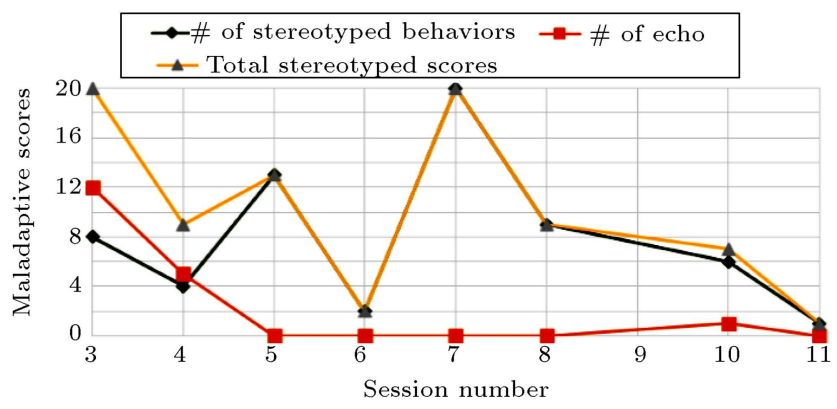

Figure 17. Maladaptive behaviors scores for S2-I (LF); stereotyped behaviors, echo/meaningless repetition of a word/words, and total scores. 


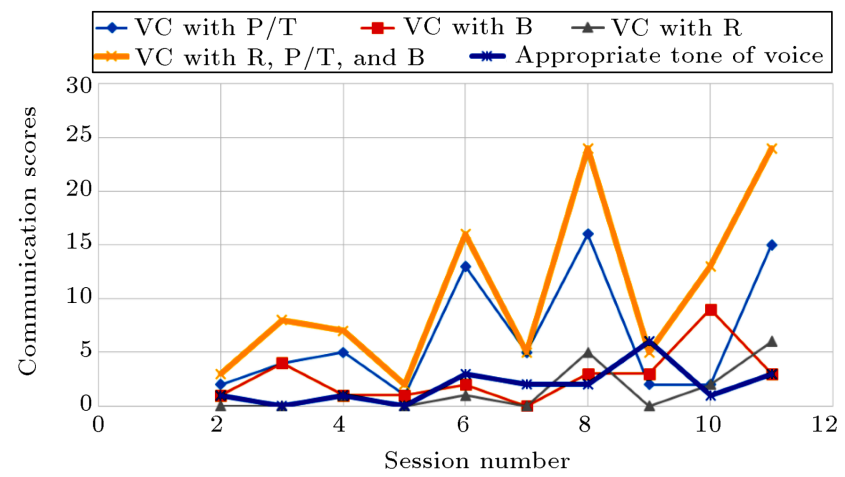

Figure 18. Verbal Communication (VC) scores for S1-A (HF) versus intervention sessions with the

Parent/Therapist $(\mathrm{P} / \mathrm{T})$, the twin Brother $(\mathrm{B})$, and the Robot $(\mathrm{R})$ in using appropriate tone of voice during the communication.

S1-A's total communication scores and intervention time, linear regression analysis was carried out using Minitab. Since the results of analysis of the variance generated are $F=5.64, p=0.045<0.05$, the linear model is statistically significant. Therefore, S1-A's verbal communication, including using a word, phrase, or a question to communicate with others, increased over the course of the interventions. In the last 4 sessions, he showed appropriate amounts of verbal communication with the therapist/parent, his twin brother, and the robot. This graph shows potential improvement in communication and social interaction skills of children with high-functioning autism. Similar to our observations, in $[1,10,22,23]$, improvement in communication and interaction skills of the children with ASD has also been reported.

Reflective of the low ability of S2-I in verbal communication, he only received total scores of 2,1 , and 8 for verbal communication with the parent/therapist, the brother, and the robot, respectively, which were not comparable to the scores of his high-functioning twin brother. It is interesting to note that 3 of his communication behaviors with the robot occurred in session 11.

We can also add that involving the twins with autism in group games caused them to slightly get out of their solitary inner world; therefore, they could experience some helpful social and communication situations. As a result, running robotic games, which concentrated on group and social skills, led to some cognitive rehabilitation in the twins.

\subsubsection{Instruction perception}

Regarding instruction perception and cooperation, S1A showed slight improvement. His concentration on the games' rules increased during the intervention sessions. S1-A's verbal communications with his mother and the robot in order to do his tasks well increased during our intervention sessions. He had only 2, 1, and 0 misun- derstandings in game instructions in the first 4 sessions, second 3 sessions, and last 3 sessions, respectively. In the case of S2-I, the low scores were due to the nature of the scenarios. We observed that his perception and cooperation was based on the games' complexity rather than session number. The minimum and maximum instruction perception percentages for S2-I were $71.9 \%$ (in session 3) and 100\% (in session 6), respectively.

In general, what stands out in the results obtained from the quantitative content analysis of the video records is S1-A's probable improvement in social interactions, and S2-I's decrease in autistic detrimental behaviors. In other words, it can be stated that robotic group games had the potential to improve social behaviors and interactions in the child with highfunctioning autism and lower the amount of stereotyped and detrimental behaviors in the child with lowfunctioning autism.

\section{2. $G A R S$}

The mother of the subjects was asked to fill in the GARS questionnaire one week before and one week after the program. It should be noted that higher scores indicated higher severity of autism. The scores are presented in Figure 19.

Figure 19 shows the assessment of the data gathered by the questionnaire. As can be seen, S1A showed an improvement in communication, aligned with the trend observed in quantitative content analysis of the video records. In addition, the mother reported no stereotyped behaviors, again agreeing with observations of the judges. The results of video records also supported the data showing decreased stereotyped behaviors, better social communication, and overall improvement in S2-I. It should be considered that the intervention scenarios were designed to contain many imitation and joint attention situations, and it has been proven that improvement in imitation and joint attention can significantly affect social and communication skills of children with autism $[1,3,5,22$ 24].

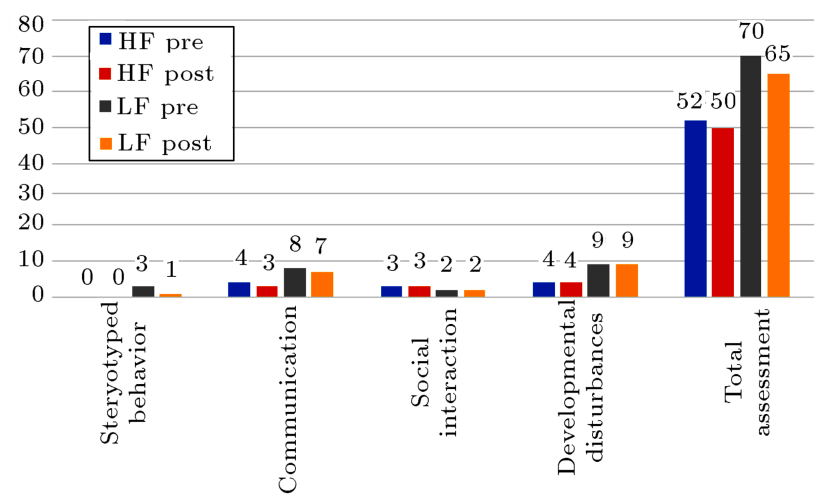

Figure 19. GARS subscales and total scores for S1-A (HF) and S2-I (LF) in pre- and post-tests. 


\subsection{Human assessment}

The twin brothers were assessed by a clinical child psychologist one week before and one week after our robot-assisted program. The criteria for this assessment consisted of more than 25 items on selfhelp skills, social interaction, verbal communications, motor skills, joint attention, and some cognitive skills (based on ESCS (Early Social Communication Scales; a comprehensive clinical measure of joint attention behaviors, behavioral requests, and social interaction behaviors of children) $[3,56,57]$, regular imitation tests, ABA treatment run in autism centers, etc.). Based on reports of the psychologist, S1-A showed more admissible progress in verbal communications and joint attention skills than in other tested skills. However, he still has problems with verbal descriptions, storytelling, visual memory, and using pronouns in sentence making. Before starting our program, S2-I's obvious problems were with verbal and percepto-motor skills; he could not perceive most of the verbal items. He also had a deficit in 3-d spatial navigation as well as understanding simple concepts, practically. According to the psychologist's report, S2-I made progress in the perception of instructions as well as in cooperation, imitation, and motor skills. He showed progress in joint attention skills and his stereotyped behaviors decreased in comparison with his past. However, she reported that S2-I's weaknesses were in mental skills and verbal communications. He still has problems with auditory memory and reasoning. All in all, he is still not qualified to start school right now. The parts of the reports including the progress of both children in joint attention skills as well as improvement of the low-functioning subject in imitation and stereotyped behaviors are quite in line with the trend of observed data from the video ratings and the GARS questionnaire presented in Subsections 3.1. and 3.2.

Fortunately, no retrogression has been reported by the clinical child psychologist for either twin. To find more reliable evidence for the type of observations in this study (i.e., investigating the long-term effects of the robot-assisted interventions on the children), it is highly recommended to do at least one more follow-up test. Unfortunately, a delayed follow-up test was not conducted in this study.

\subsection{Interview with the parents}

We had an interview with the parents of the twins after our last clinical session. The most interesting parts of the interview were as follows: "contrary to their ABA classes," the mother stated, "our kids showed inexplicable interest in taking part in imitation and turn-taking games and they were extremely happy and full of energy when leaving intervention sessions. S1-A often danced like Nima at home and sang the robot's song. For the first time since their birth, we saw the twin brothers playing a meaningful turn-taking game together with their table-soccer at home. In contrast to other classes, the twin brothers always got ready to come to your fun sessions two hours earlier and pushed us to take them to the class. They never understood that robots' actions occurred because of commands sent by an operator to the robots. They believed that Nima and Mina were their close friends, and usually missed them at home. We believed that robotic clinical intervention would have a positive effect on our children's social interaction and their communication with each other during these two months; however, we did not expect a miracle in their progress! Bringing my children to this different intervention program, I think I am doing my maternal duties better than the past."

The overall findings of this study show that using robots in treatment of children with autism was quite effective for our both high- and low-functioning participants. However, the effects seem to be different for children from different points on the autism spectrum. In imitation and joint attention skills, the child with low-functioning autism showed more potential for improvement with the robot-assisted therapy program. This research was a pilot study and based on a single subject design experiment to obtain proof for the concept in a short time (a compact two-sessions-a-week study); therefore, similar to the other single subject design $[5,40]$ and case-study researches $[1,2,37,58]$, generalizing the findings would require further research in larger-scale groups. It should be noted that the observed progress in the cognitive and social skills of our participants is due to the existence of two simultaneous factors: a) the robots' attendance in intervention sessions as a co-therapist, and b) the nature of the designed therapeutic games; and we could not separate the effects of either factor on the twins' improvements individually. In order to have a comprehensive basic analysis of whether the games or the robots are more effective, future research could be done by replacing the robots with cartoon characters or humans during the same intervention scenarios. Quantifying the behavioral analysis of the twins was one of the noteworthy aspects of this study.

Based on our observation, the child with highfunctioning autism got more deeply involved in "more robot-centric games" (i.e., games \#1, \#4 in the RobotChild mode, and \#6) than his low-functioning twin brother. This was because of his higher communication and verbal skills, which gave him many opportunities to communicate with the robot. However, in this work, we concentrated on the effects of the overall designed scenario (including all the games) on the twins. In future work, we can separate the effects of more robot-centric games and less robot-centric games to see which kinds of robotic games have more positive effects on children 
with autism. Also, for investigating the joint attention and/or imitation skills of children with autism in detail, it is recommended to reduce the number/diversity of the games in future interventions. Moreover, we are still unable to answer the question of whether conducting the same scenarios with a human-therapist (and without robots) would be more/less effective than the robot-assisted interventions for children with ASD; and to this end, multiple-baseline single-subject-design studies should be done in the future.

Although a) the small number of the participants, b) children's maturation, c) potential effects of the other classes outside our sessions, d) unpredicted behaviors of the subjects (especially the low-functioning twin) during the sessions, e) technical engineering issues, and $\mathrm{f}$ ) the small number of intervention sessions were the most important limitations of our study, the positive signal potentials discussed in this preliminary exploratory study are promising and can shed light for continuing autism treatment using robotic technology in Iran.

In addition to robot-assisted autism therapy, the Social \& Cognitive Robotics Laboratory has been involved in other applications of humanoid social robots to improve pediatric education, anxiety, and distress in children suffering from various forms of disabilities [59-69].

\section{Conclusion}

The results indicated improvement in the highfunctioning subject's social and communication skills by the two-and-a-half-month robotic treatment. In the case of the low-functioning subject, no significant improvement was observed in terms of his social skills. However, his stereotyped behaviors decreased during the course of the program. Moreover, both participants seemed to have better communication after the treatment. As the subjects' mother claimed, for the first time in 7 years, she had found the twin brothers playing a meaningful game together at home. This could be due to the robot-child-brother/parent group games the subjects were involved in. Our observations showed that the robot-assisted treatment lowered the severity of autism in the low-functioning subject and improved the communication skills in the high-functioning subject. In other words, the robotassisted clinical interventions seemed to be helpful for both low- and high-functioning children with autism. However, the progress rate turned out to be much more significant in the child with high-functioning autism in high-level cognitive skills. In the case of low-level cognitive skills, in which we usually face the ceiling effect in the high-functioning subject, robot-assisted clinical interventions seemed to be more beneficial to the participant with low-functioning autism. It should be noted that because of the small number of studied participants in single subject design studies $[37,40]$, there are no strong claims on generalizing the findings to other children with ASDs. Due to the design of the study, the assessments' focus was comparing each child's observed behaviors with his previous performance while there were many limitations in quantifying this kind of behavioral data as well as analyzing it statistically. Through various observations, we discovered the potential for using humanoid robots in the treatment of children with autism, as mentioned in this paper. In order to have a deeper investigation into the impact of the designed scenarios on children with autism, one can replicate the same/modified items using robots with clothes, or humans/cartoon characters instead of the robots. We also observed that "more robot-centric games" were more beneficial to a child with higher cognitive skills (i.e., the high-functioning participant S1-A); however, more research is required to investigate which kinds of robot-assisted games are more effective in autism research.

\section{Acknowledgement}

Our profound gratitude goes to the "Center for the Treatment of Autistic Disorders (CTAD)" and its psychologists for their contributions to the clinical trials with the children with autism. This research was funded by grant number 103 provided by the "Cognitive Sciences and Technology Council" (CSTC) of Iran (http://www.cogc.ir/). We also appreciate the Iranian National Science Foundation (INSF) for their complementary support of the Social \& Cognitive Robotics Laboratory (http://en.insf.org/).

\section{References}

1. Scassellati, B., Admoni, H., and Mataric, M. "Robots for use in autism research", Annual Review of Biomedical Engineering, 14, pp. 275-294 (2012).

2. Diehl, J.J., Schmitt, L.M., Villano, M., and Crowell, C.R. "The clinical use of robots for individuals with autism spectrum disorders: A critical review", Research in Autism Spectrum Disorders, 6(1), pp. 249262 (2012).

3. Pouretemad, H., Diagnosis and Treatment of Joint Attention in Autistic Children, (in Persian), Tehran, Iran Arjomand (2011).

4. Mavadati, S.M., Feng, H., Gutierrez, A., and Mahoor, M.H. "Comparing the gaze responses of children with autism and typically developed individuals in humanrobot interaction", In Humanoid Robots (Humanoids), 2014 14th IEEE-RAS International Conference, pp. 1128-1133 (November 2014). 
5. Taheri, A.R., Alemi, M., Meghdari, A., PourEtemad, H.R., and Basiri, N.M., "Social robots as assistants for autism therapy in Iran: Research in progress", In Robotics and Mechatronics (ICRoM), 2014 Second RSI/ISM International Conference, pp. 760-766, IEEE (October 2014).

6. Robins, B., Dickerson, P., Stribling, P., and Dautenhahn, K. "Robot-mediated joint attention in children with autism: A case study in robot-human interaction", Interaction Studies, 5(2), pp. 161-198 (2004).

7. Kozima, H., Nakagawa, C., and Yasuda, Y. "Interactive robots for communication-care: A case-study in autism therapy", In Robot and Human Interactive Communication, ROMAN 2005, IEEE International Workshop, pp. 341-346 (August 2005).

8. Pioggia, G., Sica, M.L., Ferro, M., Igliozzi, R., Muratori, F., Ahluwalia, A., and Rossi, D.D. "Humanrobot interaction in autism: FACE, an android-based social therapy", In Robot and Human Interactive Communication, 2007. RO-MAN 2007, The 16th IEEE International Symposium, pp. 605-612 (August 2007).

9. Liu, C., Conn, K., Sarkar, N., and Stone, W. "Online affect detection and robot behavior adaptation for intervention of children with autism", Robotics, IEEE Transactions on, 24(4), pp. 883-896 (2008).

10. Feil-Seifer, D. and Matarić, M.J. "Toward socially assistive robotics for augmenting interventions for children with autism spectrum disorders", In Experimental Robotics, pp. 201-210, Springer Berlin Heidelberg (2009).

11. Wainer, J., Dautenhahn, K., Robins, B., and Amirabdollahian, F. "A pilot study with a novel setup for collaborative play of the humanoid robot KASPAR with children with autism", International Journal of Social Robotics, 6(1), pp. 45-65 (2014).

12. Fujimoto, I., Matsumoto, T., De Silva, P.R.S., Kobayashi, M., and Higashi, M. "Mimicking and evaluating human motion to improve the imitation skill of children with autism through a robot", International Journal of Social Robotics, 3(4), pp. 349-357 (2011).

13. Shamsuddin, S., Yussof, H., Ismail, L., Mohamed, S., and Hanapiah, F. "Initial response in HRI-a case study on evaluation of child with autism spectrum disorders interacting with a humanoid robot NAO", Procedia Engineering, 41, pp. 1448-1455 (2012).

14. Meghdari, A., Alemi, M., Pouretemad, H., Taheri, A., Mahboob Basiri, N., Roshani Neshat, A., Nasiri, N., and Aghasizadeh, M. "Utilizing humanoid robots in teaching motor and social skills to children with autism", 3rd Basic and Clinical Neuroscience Conference, Tehran, Iran (2014).

15. Salvador, M., Silver, S., and Mahoor, M. "An emotion recognition comparative study of autistic and typically developing children using the Zeno robot", Interna- tional Conference on Robotics and Automation, IEEE, Seattle, USA (2015).

16. Begum, M., Serna, R.W., Kontak, D., Allspaw, J., Kuczynski, J., Yanco, H.A., and Suarez, J. "Measuring the efficacy of robots in autism therapy: How informative are standard HRI metrics", In Proceedings of the Tenth Annual ACM/IEEE International Conference on Human-Robot Interaction, pp. 335-342 (March 2015).

17. Khosla, R., Nguyen, K., and Chu, M.T. "Socially assistive robot enabled home-based care for supporting people with autism", In PACIS, p. 12 (2015).

18. Kajopoulos, J., Wong, A.H.Y., Yuen, A.W.C., Dung, T.A., Kee, T.Y., and Wykowska, A. "Robot-assisted training of joint attention skills in children diagnosed with autism", In International Conference on Social Robotics, Paris, France, pp. 296-305, Springer (2015).

19. Ravindra, P., De Silva, S., Tadano, K., Saito, A., Lambacher, S.G., and Higashi, M. "Therapeutic-assisted robot for children with autism", In Intelligent Robots and Systems, IROS 2009. IEEE/RSJ Int. Conf., pp. 3561-3567 (October 2009).

20. Duquette, A., Michaud, F., and Mercier, H. "Exploring the use of a mobile robot as an imitation agent with children with low-functioning autism", Autonomous Robots, 24(2), pp. 147-157 (2008).

21. Boccanfuso, L., Barney, E., Foster, C., Ahn, Y.A., Chawarska, K., Scassellati, B., and Shic, F. "Emotional robot to examine different play patterns and affective responses of children with and without ASD", In 2016 11th ACM/IEEE International Conference on Human-Robot Interaction (HRI), pp. 19-26, IEEE (March 2016).

22. Pioggia, G., Ferro, M., Sica, M.L., Dalle Mura, G., Casalini, S., De Rossi, D., and Muratori, F. "Imitation and learning of the emotional behaviour: towards an android-based treatment for people with autism", In Proceedings of Sixth International Conference on Epigenetic Robotics: Modeling Cognitive Development in Robotic Systems (2006, September).

23. Robins, B., Dautenhahn, K., Te Boekhorst, R., and Billard, A. "Robotic assistants in therapy and education of children with autism: Can a small humanoid robot help encourage social interaction skills?", Universal Access in the Information Society, 4(2), pp. 105120 (2005).

24. Werry, I., Dautenhahn, K., Ogden, B., and Harwin, W. "Can social interaction skills be taught by a social agent? The role of a robotic mediator in autism therapy", In Cognitive Technology: Instruments of Mind, pp. 57-74, Springer Berlin Heidelberg (2001).

25. Kean, J.M. "The development of social skills in autistic twins", The New Zealand Medical Journal, 81(534), pp. 204-207 (1975). 
26. Folstein, S. and Rutter, M. "Infantile autism: a genetic study of 21 twin pairs", Journal of Child Psychology and Psychiatry, 18(4), pp. 297-321 (1977).

27. Steffenburg, S., Gillberg, C., Hellgren, L., Andersson, L., Gillberg, I.C., Jakobsson, G., and Bohman, M. "A twin study of autism in Denmark, Finland, Iceland, Norway and Sweden", Journal of Child Psychology and Psychiatry, 30(3), pp. 405-416 (1989).

28. Wong, C.C.Y., Meaburn, E.L., Ronald, A., et al. "Methylomic analysis of monozygotic twins discordant for autism spectrum disorder and related behavioral traits", Molecular Psychiatry, 19(4), pp. 495-503 (2014).

29. Taniai, H., Nishiyama, T., Miyachi, T., Imaeda, M., and Sumi, S. "Genetic influences on the broad spectrum of autism: Study of proband-ascertained twins", American J. of Medical Genetics, Part B: Neuropsychiatric Genetics, 147(6), pp. 844-849 (2008).

30. Mitchell, S.R., Reiss, A.L., Tatusko, D.H., et al. "Neuroanatomic alterations and social and communication deficits in monozygotic twins discordant for autism disorder", The American Journal of Psychiatry, 166(8), pp. 917-925 (2009).

31. Ho, A., Todd, R.D., and Constantino, J.N. "Brief report: autistic traits in twins vs. non-twins-a preliminary study", Journal of Autism and Developmental Disorders, 35(1), pp. 129-133 (2005).

32. Constantino, J.N. and Todd, R.D. "Autistic traits in the general population: a twin study", Archives of General Psychiatry, 60(5), pp. 524-530 (2003).

33. Bolton, P., Macdonald, H., Pickles, A., Rios, P.A., Goode, S., Crowson, M., and Rutter, M. "A casecontrol family history study of autism", Journal of Child Psychology and Psychiatry, 35(5), pp. 877-900 (1994).

34. Folstein, S. and Rutter, M. "Infantile autism: a genetic study of 21 twin pairs", Journal of Child psychology and Psychiatry, 18(4), pp. 297-321 (1977).

35. Bailey, A., Bolton, P., Butler, L., Couteur, A., Murphy, M., Scott, S., and Rutter, M. "Prevalence of the fragile $\mathrm{X}$ anomaly amongst autistic twins and singletons", Journal of Child Psychology and Psychiatry, 34(5), pp. 673-688 (1993).

36. Sultana, R., Yu, C.E., Yu, J., et al. "Identification of a novel gene on chromosome 7q11. 2 interrupted by a translocation breakpoint in a pair of autistic twins", Genomics, 80(2), pp. 129-134 (2002).

37. Hilton, J.C. and Seal, B.C. "Brief report: comparative $\mathrm{ABA}$ and DIR trials in twin brothers with autism", Journal of Autism and Developmental Disorders, 37(6), pp. 1197-1201 (2007).

38. Geschwind, D.H. "Advances in autism", Annual Review of Medicine, 60, p. 367 (2009).
39. Burack, J.A. and Volkmar, F.R. "Development of low-and high-functioning autistic children", Journal of Child Psychology and Psychiatry, 33(3), pp. 607-616 (1992).

40. Engel, R.J. and Schutt, R.K., The Practice of Research in Social Work, Sage Publications, Chapter 7 (2016).

41. https://www.aldebaran.com/en (March. 2016).

42. http://www.hansonrobotics.com/ (March. 2016).

43. Gilliam, J.E., Gilliam Autism Rating Scale: Examiner's Manual, Pro-Ed (1995).

44. Ashburner, J., Ziviani, J., and Rodger, S. "Sensory processing and classroom emotional, behavioral, and educational outcomes in children with autism spectrum disorder", American Journal of Occupational Therapy, 62(5), pp. 564-573 (2008).

45. Ahmadi, S.J., Safari, T., Hemmatian, M., and Khalili, Z. "Exploring the criterion of diagnosing autism (GARS)", (in Persian), Journal of Researchers of Cognitive and Behavioral Sciences, 1(1), pp. 87-104 (2012).

46. Neuendorf, K.A. and Kumar, A. "Content analysis", The International Encyclopedia of Political Communication (2006).

47. Riff, D., Lacy, S., and Fico, F., Analyzing Media Messages: Using Quantitative Content Analysis in Research, Routledge (2014).

48. Rimland, B. and Edelson, S., Autism Treatment Evaluation Checklist: Statistical Analyses, Autism Research Institute (2000).

49. Bellini, S., Autism Social Skills Profile, Shawnee Mission (KS): Autism Asperger Publishing (2006).

50. Bellini, S. and Peters, J.K. "Social skills training for youth with autism spectrum disorders", Child and Adolescent Psychiatric Clinics of North America, 17(4), pp. 857-873 (2008).

51. Minitab 17 Statistical Software [Computer software], State College, PA: Minitab, Inc. (www.minitab.com) (2010).

52. Warren, Z.E., Zheng, Z., Swanson, A.R., Bekele, E., Zhang, L., Crittendon, J.A., and Sarkar, N. "Can robotic interaction improve joint attention skills?", Journal of Autism and Developmental Disorders, 45(11), pp. 3726-3734 (2015).

53. Whalen, C. and Schreibman, L. "Joint attention training for children with autism using behavior modification procedures", Journal of Child Psychology and Psychiatry, 44(3), pp. 456-468 (2003).

54. Ingersoll, B. and Gergans, S. "The effect of a parentimplemented imitation intervention on spontaneous imitation skills in young children with autism", Research in Developmental Disabilities, 28(2), pp. 163175 (2007). 
55. Ingersoll, B. and Schreibman, L. "Teaching reciprocal imitation skills to young children with autism using a naturalistic behavioral approach: Effects on language, pretend play, and joint attention", Journal of Autism and Developmental Disorders, 36(4), pp. 487$505(2006)$

56. Mundy, P., Delgado, C., Block, J., Venezia, M., Hogan, A., and Seibert, J., Early Social Communication Scales (ESCS), Coral Gables, FL: University of Miami (2003).

57. Kasari, C., Freeman, S., and Paparella, T. "Joint attention and symbolic play in young children with autism: A randomized controlled intervention study", Journal of Child Psychology and Psychiatry, 47(6), pp. 611-620 (2006).

58. Tapus, A., Peca, A., Aly, A., et al. "Children with autism social engagement in interaction with Nao, an imitative robot-A series of single case experiments", Interaction Studies, 13(3), pp. 315-347 (2012).

59. Meghdari, A., Alemi, M., Ghaazisaidi, M., Taheri, A.R., Karimian, A., and Vakili, M.Z. "Applying robots as teaching assistant in EFL classes at Iranian middleschools", Proc. of 2013 International Conference on Education and Modern Educational Technologies, Venice, Italy, Retrieved from www.europement.com (2013, September).

60. Alemi, M., Meghdari, A., and Ghazisaedy, M. "The impact of social robotics on L2 learners' anxiety and attitude in English vocabulary acquisition", International Journal of Social Robotics, 7(4), pp. 523-535 (2015).

61. Alemi, M., Ghanbarzadeh, A., Meghdari, A., and Moghadam, L.J. "Clinical application of a humanoid robot in pediatric cancer interventions", International Journal of Social Robotics, 8(5), pp. 743-759 (2016).

62. Alemi, M., Meghdari, A., and Ghazisaedy, M. "Employing humanoid robots for teaching English language in Iranian junior high-schools", International Journal of Humanoid Robotics, 11(03), p. 1450022 (2014).

63. Alemi, M., Meghdari, A., Mahboub Basiri, N., and Taheri, A. "The effect of applying humanoid robots as teacher assistants to help Iranian autistic pupils learn English as a foreign language", Lecture Notes in Computer Science (LNCS): Social Robotics, 9388, pp. 1-10 (2015).

64. Saffari, E., Meghdari, A., Vazirnezhad, B., and Alemi, M. "Ava (a social robot): Design and performance of a robotic hearing apparatus", Lecture Notes in Computer Science (LNCS): Social Robotics, 9388, pp. 440-450 (2015).

65. Taheri, A.R., Meghdari, A., Alemi, M., Pouretemad, H., Poorgoldooz, P., and Roohbakhsh, M. "Social robots and teaching music to autistic children: Myth or reality?", Lecture Notes in Computer Science (LNCS): Social Robotics, 9979, pp. 541-550 (2016).

66. Meghdari, A., Alemi, M., Pour, A.G., and Taheri, A.R. "Spontaneous human-robot emotional interaction through facial expressions", Lecture Notes in Computer Science (LNCS): Social Robotics, 9979, pp. 351361 (2016).

67. Zakipour, M., Meghdari, A., and Alemi, M. "RASA: A low-cost upper-torso social robot acting as a sign language teaching assistant", Lecture Notes in Computer Science (LNCS): Social Robotics, 9979, pp. 630-639 (2016).

68. Meghdari, A., Alemi, M., Khamooshi, M., Amoozandeh, A., Shariati, A., and Mozafari, B. "Conceptual design of a social robot for pediatric hospitals", In 2016 4th International Conference on Robotics and Mechatronics (ICROM), pp. 566-571, IEEE (October 2016). DOI: 10.1109/ICRoM.2016.7886804

69. Meghdari, A., Bagheri Shouraki, S., Siamy, A., and Shariati, A. "The real-time facial imitation by a social humanoid robot", In 2016 4th International Conference on Robotics and Mechatronics (ICROM), pp. 566-571, IEEE (October 2016). DOI: 10.1109/ICRoM.2016.7886797

\section{Biographies}

Alireza Taheri received his $\mathrm{PhD}$ in Mechanical Engineering with emphasis on Social Robotics at Sharif University of Technology, Tehran, Iran. In 2016-2017, he spent a total of one-year sabbatical as a research scholar at the Yale University and the University of Denver, USA.

Ali Meghdari is a Professor of Mechanical Engineering at Sharif University of Technology (SUT) in Tehran. Professor Meghdari has performed extensive research in various areas of robotics, including social and cognitive robotics, mechatronics, biorobotics, and modelling of biomechanical systems. He has been the recipient of various scholarships and awards, the latest being the 2012 Allameh Tabataba'i Distinguished Professorship Award by the National Elites Foundation of Iran (BMN); the 2001 Mechanical Engineering Distinguished Professorship Award from the Ministry of Science, Research \& Technology (MSRT) in Iran; and the 1997 ISESCO Award in Technology from Morocco. He is currently the Director of the Centre of Excellence in Design, Robotics and Automation (CEDRA), an affiliate member of the Iranian Academy of Sciences (IAS), and a fellow of the American Society of Mechanical Engineers (ASME).

Minoo Alemi received her $\mathrm{PhD}$ in Applied Linguistics (TEFL) from Allameh Tabataba'i University in 2011. She is an Assistant Professor and Division Head 
of Applied Linguistics at Islamic Azad University, West Tehran Branch, Iran. She is the founder of Robot-Assisted Language Learning (RALL) and the co-founder of Social Robotics in Iran in which she was involved as a post-doctoral research associate at the Social \& Cognitive Robotics Laboratory of Sharif University of Technology. Her areas of interest include discourse analysis, interlanguage pragmatics, social robotics, and RALL. Dr. Alemi has been the recipient of various teaching and research awards from Sharif University of Technology; Allameh Tabataba'i University; Islamic Azad University; and International
Conference on Social Robotics (ICSR2014), Sydney, Australia. She has published over 75 papers and books in refereed national and international conferences, and journals.

Hamid Reza Pouretemad is a Professor of Education and Psychology in Institute for Cognitive and Brain Sciences, Shahid Beheshti University, Tehran, Iran. He has done extensive research on children with autism spectrum disorders. He has published over 150 papers in refereed national and international conferences, and journals. 